\title{
Milk and Dairy Products: Dietary Partners for Life?
}

\author{
Givens $\mathrm{DI}^{1,3^{*}}$ and Hobbs DA ${ }^{2,3}$
}

${ }^{1}$ Food Production and Quality Division and Centre for Food Security, University of Reading, Reading RG6 6AR, UK

${ }^{2}$ Hugh Sinclair Unit of Human Nutrition, Department of Food and Nutritional Sciences, School of Chemistry Food and Pharmacy, University of Reading, UK

${ }^{3}$ Institute for Cardiovascular and Metabolic Research (ICMR), University of Reading, UK

"Corresponding author: Professor lan Givens, Department of Food Production and Quality Division and Centre for Food Security, Faculty of Life Sciences, University of Reading, Reading RG6 6AR, UK, Tel: +44 (0) 118378 8491; E-mail: d.i.givens@reading.ac.uk

Rec date: Jan 28, 2014; Acc date: Jul 16, 2014; Pub date: Jul 26, 2014

Copyright: (c) 2014 Givens DI, et al. This is an open-access article distributed under the terms of the Creative Commons Attribution License, which permits unrestricted use, distribution, and reproduction in any medium, provided the original author and source are credited.

\begin{abstract}
The importance of milk in the human diet as a supplier of energy, high quality protein and other key nutrients, including calcium, is broadly accepted yet in the mind of many there remains uncertainty about whether or not these foods contribute to increased risk of cardiovascular and other chronic diseases. The evidence from long term prospective cohort studies that high milk consumption does not increase cardiovascular disease risk and indeed may provide benefit is now pretty unequivocal, although the effects of butter and cheese and benefits of fat reduced milk and saturated fat reduced milk are less certain. Milk is a crucial supplier of calcium, phosphorus and magnesium for bone growth and development in children and it is concerning that due to reduced milk consumption intake of these nutrients is often sub-optimal, particularly for female children. In addition, specific health issues in pregnant women and the elderly can be alleviated by milk or components of milk and these effects are not all explained by traditional nutrition.
\end{abstract}

\section{Keywords: Diary; Diet; Health; Nutrition; Cardiovascular}

\section{Introduction}

Public health nutrition is facing many major challenges and three of these will shape food-related policy for decades to come. These are the rapidly increasing burden of obesity, the increasing age of populations and the challenge of increasing world food production by some $50 \%$ by 2030 to meet the increasing demands [1] whilst minimising the effect on the environment. The first two forces in particular will increase the risk of chronic disease substantially and the third will have other, perhaps obvious risks. This means that diet, a key moderator of chronic disease risk will play an increasingly important role. The marked rise in obesity and related type 2 diabetes is of particular concern since it is now also beginning to affect younger people [2]. In the UK, the recent Foresight Report on obesity predicts that by 2050 some $55 \%$ of UK adults will be obese [3]. Similarly, projections to 2050 of the age structure of the EU 25 suggest that its old-age dependency ratio (the number of people aged 65 and over relative to those between 15 and 64) will double to $54 \%$ by 2050 [4]. The outcome of these trends will, if not moderated, lead to unsustainable costs of health care.

Food production in the future will have to balance many factors, environmental cost, financial cost but crucially their role in reducing the risk of chronic disease. Animal-derived foods in particular have been highlighted as having a high environmental cost but much less attention has been paid to their role in healthy diets that have impact from childhood to old age.

\section{Milk and Children}

As early as 1926, the UK Medical Research Council identified that daily consumption of an extra $568 \mathrm{~mL}$ of milk per day by boys gave rise to a sizeable increase in growth [5]. This formed the basis of the school milk policy which is now almost non-existent in the UK, yet the value of milk for children remains recognised and in 2000 the UN Food and Agriculture Organisation declared a World School Milk Day.

Special concern focuses on the mineral/trace element intakes of children and young people. Adequate dietary calcium, phosphorus and magnesium supply is essential for optimal bone growth. A sub-optimal calcium intake reduces bone density more quickly than it affects growth [6] and there are now cases of rickets re-emerging in the UK. In the UK, calcium intake in children aged 7 to 18 years of age is now substantially sub-optimal, especially in girls [7]. This is of particular concern because many individuals in the UK also have sub-optimal vitamin D status which would further contribute to reduced bone development. Milk and dairy products are rich sources of dietary calcium and the fall in milk consumption over recent years is no doubt a key contributor to the observed sub-optimal calcium intake by many children.

Milk and dairy products are also good sources of magnesium of which adequate intakes are especially important during the phase of rapid bone growth in adolescence. A recent study in the USA indicated that except for children and adolescents with very low calcium intakes, magnesium intake may be more important in relation to bone development [8]. The study was based on 63 healthy children aged four to eight years, none of whom were taking vitamin or mineral supplements showed that although calcium intake was not significantly associated with total bone mineral content or density, intake of magnesium and the amount absorbed were key predictors of bone mass. However, the extent to which these results can be extrapolated to the general population is of course uncertain and therefore additional large-scale studies in this area are needed.

There is also now evidence of that many young women has suboptimal iodine status, especially during pregnancy. Moreover recent 
findings show that children born to women of sub-optimal status have a slower cognitive development than those from women of adequate status [9]. Milk is the main source of dietary iodine and whilst the reduced status in young women is almost certainly the result of reduced consumption, the problem has highlighted how variable milk iodine concentration can be. On average, milk in summer has about half the iodine concentration of winter milk and in equivalent seasons, organic milk has about half the concentration of conventional milk [10].

\section{Milk and Dairy Products in Adulthood}

\section{Milk consumption and cardiovascular disease}

Many conclusions about the risk of Cardiovascular Disease (CVD) resulting from consumption of milk and dairy products have been based on the interpretation of risk makers for disease, notable blood cholesterol. This probably provides an incomplete picture of risk and led Alvarez-Leon et al. [11] to highlight that statements about the benefits and risks of dairy product consumption appear to be based on selected physio-pathological data (such as blood cholesterol) and not on valid epidemiological evidence. Indeed, as they commented 'public health nutrition should not be unaware of the need for evidence-based conclusions'.

Although they do have limitations, for now the best evidence on dairy food consumption, health and survival, comes from long-term cohort studies with disease events and death as the outcomes. Moreover, the most reliable conclusions are those derived by combining the results from many studies in a so-called meta-analysis. To date, the largest meta-analysis for CVD is that of Elwood et al. [12] based on 17 studies judged of sufficient quality for inclusion. Together these comprised a total of 4.3 million person-years, during which16,212 heart disease events or deaths attributed to heart disease occurred. Within each study an estimate of the relative risk (RR) of cardiovascular disease and diabetes was made within a group of subjects with the highest milk/dairy consumption compared with a group of subjects with the lowest consumption. Overall, the metaanalyses showed a reduction in risk in the subjects with the highest dairy consumption relative to those with the lowest intake, i.e. 0.87 (95\% confidence interval (CI) $0.77,0.98$ ) for all-cause deaths, 0.92 (95\% CI $0.80,0.99)$ for ischaemic heart disease, 0.79 (95\% CI 0.68 , $0.91)$ for stroke and 0.85 (95\% CI $0.75,0.96)$ for incident diabetes. Stroke is of particular interest because of the clinically important reduction in blood pressure which has been repeatedly shown to be associated with a high intake of milk/dairy foods. In all types of stroke (ischaemic, haemorrhagic and subarachnoid bleed) raised blood pressure is important and the risks of all three appear to be reduced by high milk and dairy food consumption by roughly the same amount.

Hypertension is one of the leading risk factors in the development of heart disease and stroke, and is estimated to be responsible for around $13 \%$ of all deaths worldwide [13]. As noted above, there are now many studies which show a reducing effect of milk and dairy product consumption on blood pressure $[14,15]$. However, in addition to effects on blood pressure, the effect of milk/dairy foods on new, more holistic markers of vascular health such as vascular stiffness is becoming evident. Both cross-sectional [16] and longitudinal [14] cohort studies have shown significant negative relationships between dairy product intake and measures of arterial stiffness. Studies are limited in number, but suggest that milk proteins probably play a key part in reducing both blood pressure and arterial stiffness.
Because of its link to obesity, Type 2 diabetes is another major disease of interest. The meta-analysis of Elwood et al. [12] involving a total of 7,779 new cases of diabetes during 1.7 million person years showed a $15 \%$ overall reduction in diabetes (RR 0.85; 95\% CI,0.75, 0.96)associated with a high milk/dairy intake. It is particularly interesting that two recent studies $[17,18]$ have suggested a substantial negative relationship between one of the minor fatty acids present in milk fat (trans-palmitoleic acid) and risk of diabetes. Time will tell if this reflects a real mechanism.

\section{Dairy food consumption and cancer}

Relationships between dairy food consumption and cancer were examined in detail by the World Cancer Research Fund and the American Institute for Cancer Research [19]. Their report stated that milk consumption probably protects against colorectal cancer (RR 0.78 ; 95\% CI, 0.69, 0.88), possibly bladder cancer (RR 0.82; 95\% CI, $0.67,0.99)$, but is associated with a possible increase in prostate cancer (RR 1.05; 95\% CI, 0.98, 1.14). An updated meta-analysis [20] was based on a total of 19 cohort studies with more than one million subjects, of which 11,579 developed colon cancer. The results showed that milk and total (i.e. all types) dairy products, but not cheese or other dairy products (mainly butter, yoghurt, ice cream and fermented milk), were associated with a reduction in colorectal cancer risk. The summary RR were $0.83(95 \% \mathrm{CI}, 0.78,0.88)$ per $400 \mathrm{~g} /$ day of total dairy products and $0.91(95 \% \mathrm{CI}, 0.85,0.94)$ per $200 \mathrm{~g} /$ day of milk intake.

These relationships with cancer are poorly understood at present, though a beneficial effect on colon cancer risk has also been reported with calcium supplements. Much more work on this subject is needed.

\section{Dairy and body weight regulation}

The intervention studies which have evaluated the impact of dairy products on body weight regulation can be broadly separated into two groups; those with and without energy restriction. For the studies without energy restriction, bone health rather than body weight often represented the primary measures, and in these studies little evidence for a beneficial effect of milk or dairy products on body weight or fat mass emerges [21,22]. Although inconsistencies exist, partly due to small sample sizes, insufficient study durations, differences in study design and the diversity of study population, there is more positive evidence linking milk and dairy consumption with more effective weight loss, in particular fat loss and lean mass maintenance, under energy restriction [23-25]. Moreover, the data suggest a calcium threshold effect with greater impact on adiposity evident in cohorts with a low [25] versus high habitual calcium intake [26]. Zemel et al. [27] showed that obese individuals placed on an energy restricted diet $(-2.1 \mathrm{MJ} / \mathrm{d})$, with (test group $1100 \mathrm{mg} / \mathrm{d}$ calcium) or without (control group 400-500 mg calcium per day) a yogurt drink, experienced fat losses of $-4.4 \mathrm{~kg}$ and $-2.8 \mathrm{~kg}(\mathrm{P}<0.005)$ in the test compared with the control group at 12 weeks, with associated reductions in waist circumferences of -4 and $-1 \mathrm{~cm}(\mathrm{P}<0.005)$.

With respect to potential mechanisms of action any effect of dairy products on weight maintenance has been attributed to calcium and its effect on fat absorption, lipid oxidation and adipocyte lipid metabolism [28,29]. However, the observation that calcium administered as dairy may be more effective in weight loss and weight maintenance relative to calcium supplementation [30] is suggestive 
Page 3 of 4

that other components of dairy products may also have a role in body weight regulation.

Taken together, these data suggest that dairy products may have modest beneficial effect in facilitating weight loss only when energy is restricted [31]. There is a need for robustly designed intervention studies that clearly define the primary outcome to elucidate if dairy products can increase weight loss and/or improve weight maintenance.

\section{Milk and Dairy Products and the Elderly}

Partly because of the increased life expectancy, there is growing concern about increased prevalence of dementia with the numbers in the UK projected to double by 2040 [32]. There are few studies which have examined any relationship between milk consumption and risk of dementia. One study which did is the Adult Health Study [33], a prospective cohort of 1,774 subjects in Hiroshima, Japan born before September 1932. Between 1992 and 1997, 1,660 were shown to have no dementia whilst 114 had dementia (51 with Alzheimer's disease, 38 with vascular dementia). Vascular dementia prevalence increased significantly with age, with higher systolic blood pressure and crucially, with lower milk intake. The mechanism whereby milk provided protection cannot be stated with certainty but given other evidence linking milk consumption with lowered blood pressure, it would seem probable that this mechanism was involved. Clearly much further research is needed in this area.

Another increasing problem of the elderly is loss of skeletal muscle mass and strength, also known as sarcopenia, which is linked with a progressive decline in functional performance and increased risk of bone breakages following a fall. It has been known for some time that resistance exercise training can reduce loss of muscle and improve overall strength but more recently the value of dietary protein has been identified. In particular it was shown that whey protein was more effective at reducing muscle mass than soya protein especially if consumed after exercise [34]. Whey protein is widely used by the sports industry but the future may see it have a key role in diets of older people.

\section{Conclusions}

Milk and milk products have had a very mixed press in recent times from being blamed for many disorders to more measured considerations of their role in a balanced diet. Whilst most people know they are very important sources of dietary nutrients such as calcium and iodine, there is more uncertainty about whether or not these foods contribute to increased risk of cardiovascular and other chronic diseases. The evidence from long term cohort studies that high milk consumption does not increase CVD risk and indeed may provide benefit is now pretty unequivocal, although the effects of butter and cheese as well as benefits of fat reduced milk and saturated fat reduced milk are less certain. There is now good evidence that specific health issues related to children, pregnant women and the elderly can be alleviated by milk or components of milk and these effects are not all explained by traditional nutrition. They must however be considered when debating future sustainable food production; for example, a simplistic replacement of milk proteins by plant proteins may not provide the same long term health benefits.

\section{Acknowledgements}

This work was supported by Dairy Co, a division of the UK Agriculture and Horticulture Development Board. All authors contributed to, and approved, the final version of the manuscript. There are no conflicts of interest.

\section{References}

1. House of Commons (2009) Securing food supplies up to 2050: the challenges faced by the UK. Environment, Food and Rural Affairs Committee.

2. Nugent A (2004) The metabolic syndrome. Nutr Bull 29: 36-43.

3. Butland B, Jebb S, Kopelman P, McPherson K, Thomas S, et al. (2007) Foresight Future Choices -Project Report Tackling Obesities: 2nd Edn

4. Carone G, Costello D (2006) Can Europe Afford to Grow Old? Finance and Development. Vol: 43

5. Corry Mann HC (1926) Diets for boys during the school age. Medical Research Council Special Report Series No. 105. London: HMSO.

6. Moore T, Impey SG, Martin, P.E.N, Symonds KR (1963) Meat diets. II. Effect of the age of rats on their ability to withstand the low calcium intake induced by a diet of minced beef. J Nutr 80: 162-170.

7. Bates B, Lennox A, Bates C, Swan G (2012) National Diet and Nutrition Survey: headline results from years 1 and 2 combined of the rolling programme 2008/09-2009/10. Department of Health.

8. Abrams SA, Chen Z, Hawthorne KM (2014) Magnesium metabolism in 4-year-old to 8-year-old children. J Bone Miner Res 29: 118-122.

9. Bath SC, Steer CD, Golding J, Emmett P, Rayman MP (2013) Effect of inadequate iodine status in UK pregnant women on cognitive outcomes in their children: results from the Avon Longitudinal Study of Parents and Children (ALSPAC). Lancet 382: 331-337.

10. Bath SC, Button S, Rayman MP (2012) Iodine concentration of organic and conventional milk: implications for iodine intake. Br J Nutr 107: 935-940.

11. Alvarez-León EE, Román-Viñas B, Serra-Majem L (2006) Dairy products and health: a review of the epidemiological evidence. Br J Nutr 96 Suppl 1: S94-99.

12. Elwood PC, Pickering JE, Givens DI, Gallacher JE (2010) The consumption of milk and dairy foods and the incidence of vascular disease and diabetes: an overview of the evidence. Lipids 45: 925-39.

13. Alwan A (2011) Global Status Report on Non-communicable Diseases 2010.

14. Livingstone KM, Lovegrove JA, Cockcroft JR, Elwood PC, Pickering JE, et al. (2013) Does dairy food intake predict arterial stiffness and blood pressure in men?: Evidence from the Caerphilly Prospective Study. Hypertension 61: 42-47.

15. Griffith LE, Guyatt GH, Cook RJ, Bucher HC, Cook DJ (1999) The influence of dietary and nondietary calcium supplementation on blood pressure: an updated metaanalysis of randomized controlled trials. Am J Hypertens 12: 84-92.

16. Crichton GE, Elias MF, Dore GA, Abhayaratna WP, Robbins MA (2012) Relations between dairy food intake and arterial stiffness: pulse wave velocity and pulse pressure. Hypertension 59: 1044-1051.

17. Mozaffarian D, de Oliveira Otto MC, Lemaitre RN, Fretts AM, Hotamisligil G, et al. (2013) trans-Palmitoleic acid, other dairy fat biomarkers, and incident diabetes: the Multi-Ethnic Study of Atherosclerosis (MESA). Am J Clin Nutr 97: 854-861.

18. Mozaffarian D, Cao H, King IB, Lemaitre RN, Song X, et al. (2010) Trans-palmitoleic acid, metabolic risk factors, and new-onset diabetes in U.S. adults: a cohort study. Ann Intern Med 153: 790-799.

19. WCRF (2007) World Cancer Research Fund/American Institute for Cancer Research: Food, Nutrition, Physical Activity and the Prevention of Cancer: A Global Perspective. AICR (American Institute for Cancer Research), Washington, DC, 517. 
Citation: Givens DI, Hobbs DA (2014) Milk and Dairy Products: Dietary Partners for Life?. Primary Health Care 4: 161. doi: $10.4172 / 2167-1079.1000161$

Page 4 of 4

20. Aune D, Lau R, Chan DS, Vieira R, Greenwood DC, et al. (2012) Dairy products and colorectal cancer risk: a systematic review and metaanalysis of cohort studies. Ann Oncol 23: 37-45.

21. Lau EM, Woo J, Lam V, Hong A (2001) Milk supplementation of the diet of postmenopausal Chinese women on a low calcium intake retards bone loss. J Bone Miner Res 16: 1704-1709.

22. Gunther CW, Legowski PA, Lyle RM, McCabe GP, Eagan MS, et al (2005) Dairy products do not lead to alterations in body weight or fat mass in young women in a 1-y intervention. Am J Clin Nutr 81: 751-756.

23. Zemel MB (2005) The role of dairy foods in weight management. J Am Coll Nutr 24: 537S-46S.

24. Summerbell CD, Watts C, Higgins JP, Garrow JS (1998) Randomised controlled trial of novel, simple, and well supervised weight reducing diets in outpatients. BMJ 317: 1487-1489.

25. Zemel MB, Richards J, Milstead A, Campbell P (2005) Effects of calcium and dairy on body composition and weight loss in African-American adults. Obes Res 13: 1218-1225.

26. Thompson WG, Rostad Holdman N, Janzow DJ, Slezak JM, Morris KL et al. (2005) Effect of energy-reduced diets high in dairy products and fiber on weight loss in obese adults. Obes Res 13: 1344-1353.

27. Zemel MB, Richards J, Mathis S, Milstead A, Gebhardt L, et al. (2005) Dairy augmentation of total and central fat loss in obese subjects. Int J Obes (Lond) 29: 391-397.

28. Christensen R, Lorenzen JK, Svith CR, Bartels EM, Melanson EL, et al. (2009) Effect of calcium from dairy and dietary supplements on faecal fat excretion: a meta-analysis of randomized controlled trials. Obes Rev 10: 475-486.

29. Zemel MB, Sun X, Sobhani T, Wilson B (2010) Effects of dairy compared with soy on oxidative and inflammatory stress in overweight and obese subjects. Am J Clin Nutr 91: 16-22.

30. Zemel MB, Thompson W, Milstead A, Morris K, Campbell P (2004) Calcium and dairy acceleration of weight and fat loss during energy restriction in obese adults. Obes Res 12: 582-590.

31. Dougkas A, Reynolds CK, Givens ID, Elwood PC, Minihane AM (2011) Associations between dairy consumption and body weight: a review of the evidence and underlying mechanisms. Nutr Res Rev 24: 72-95.

32. Jagger C, Matthews R, Lindesay J, Robinson T, Croft P, et al. (2009) The effect of dementia trends and treatments on longevity and disability: a simulation model based on the MRC Cognitive Function and Ageing Study (MRC CFAS). Age Ageing 38: 319-325.

33. Yamada M, Kasagi F, Sasaki H, Masunari N, Mimori Y, et al. (2003) Association between dementia and midlife risk factors: the Radiation Effects Research Foundation Adult Health Study. J Am Geriatr Soc 51: 410-414.

34. Phillips SM, Tang JE, Moore DR (2009) The role of milk- and soy-based protein in support of muscle protein synthesis and muscle protein accretion in young and elderly persons. J Am Coll Nutr 28: 343-354. 